\title{
Effects of a 4 week touch rugby and self-paced interval running intervention on health markers in active young men
}

\author{
Nick Dobbin ${ }^{1}$ - Daniel Bloyce ${ }^{2}$ Stephen Fôn Hughes ${ }^{3} \cdot$ Craig Twist $^{2}$
}

Received: 27 July 2019 / Accepted: 6 March 2020 / Published online: 29 March 2020

(c) The Author(s) 2020

\begin{abstract}
Background Modified team sport activity has been proposed as effective exercise modality for promoting markers of health that are comparable or greater than continuous forms of activity. However, research using modified team sports is currently limited to sedentary populations using $2-3$ sessions across a minimum of 8 weeks.

Aim To investigate the effects of a 4-week touch rugby and self-paced interval running intervention on a range of health markers in active men.

Methods Sixteen participants (age 26.4 \pm 6.4 years) were matched for age, demographic and physical activity before completing a single touch rugby $(n=8)$ or running $(n=8)$ session per week for 4 weeks. Measures of systolic and diastolic blood pressure, resting heart rate (RHR), body composition and biochemical status were recorded pre- and post-intervention.

Results ANCOVA analysis revealed between-group differences for impedance $(P=0.027)$, fat mass $(P=0.008)$, percentage body fat $(P=0.008)$ and fat-free mass $(P=0.002)$, with greater changes after touch rugby. Systolic blood pressure decreased for both groups with greater reductions observed after touch rugby $(P=0.002)$. No between-group difference was observed for RHR, interleukin-6 or C-reactive protein $(P>0.05)$. Contrasting internal, external and perceptual loads were observed. Conclusion The results of this study suggest that a single session of touch rugby over a 4-week period elicited greater improvements in body composition and SBP than self-paced running, with both being equally beneficial for improving RHR, diastolic blood pressure and inflammatory status in active young men.
\end{abstract}

Keywords Team sports $\cdot$ Physical activity $\cdot$ Inflammation $\cdot$ Body composition $\cdot$ Microtechnology

\section{Introduction}

Regular physical activity (PA) has been advocated as an important prevention strategy against the development of non-communicable diseases (NCDs) [1-3]. To date, much of the literature has focused on continuous aerobic-based training such as walking, jogging or cycling [2, 4], highintensity intermittent training [5] or sporting activities [6]. The use of modified team sport activity, which refers to well-recognised sports that have been adapted (i.e. player

Nick Dobbin

N.Dobbin@mmu.ac.uk

1 Department of Health Professions, Manchester Metropolitan University, Manchester, UK

2 Department of Sport and Exercise Sciences, University of Chester, Chester, UK

3 Betsi Cadwaladr University Health Board, Wrexham Maelor Hospital, Wrexham, UK numbers, pitch size, rules and duration), is reported to be beneficial for promoting physical activity and reducing the risk of NCDs, particularly in those unresponsive to healthbased interventions [7].

Recently, the Rugby Football League introduced a touch rugby programme aimed at promoting PA in those often regarded as "hard-to-reach", including young to middle-aged males and females situated within the low socio-economic areas of the UK. The efficacy of modified team sports for improving health has been explored in untrained elderly men (65-75 years) [8], homeless men [9], middle-aged male and female $[10,11]$, and those clinically diagnosed with diabetes [12] and prostate cancer [13]. It is possible that being associated with traditional sports, recognisable, linked to professional clubs and, for those participating, feeling part of a team, developing friendships and experiencing enjoyment [14], might explain why modified team sports could be appealing for some populations. 
Typically, interventions using modified team sports have lasted between 8 and 24 weeks, indicating a dose-response relationship between duration and the magnitude of change in routine measures of health $[1,8,15,16]$. For example, Krustrup et al. [15] reported reductions in systolic (SBP), diastolic (DBP) blood pressure of 2.0 and $1.0 \mathrm{mmHg}$, respectively, after 4 weeks of modified team sport (soccer); while after 12 weeks, reductions of 8.0 and $5.0 \mathrm{mmHg}$ were observed. Similarly, RHR was reduced by 3 beats $\min ^{-1}$ after 4 weeks and 6 beats min $^{-1}$ after 12 weeks in untrained men. Modified team sports are also effective at improving body composition through reductions in body mass $(-0.2$ to $-5.4 \%)$, fat mass (FM) $(-2.9$ to $-13.6 \%)$ and percentage body fat (\%BF) $(-2.1$ to $-11.7 \%)$, as well as increasing lean body mass $(0.4-5.9 \%)$ and lower-limb bone mineral content $(0.86-3.2 \%)$ [11, 12, 15-17]. Such changes in body composition might also impact on chronic low-grade systemic inflammatory status, which refers to a prolonged elevation in concentrations of circulating cytokines, acute phase proteins and adhesion molecules [18, 19]. Indeed, it has been reported that approximately $30 \%$ of circulating IL-6 is released from adipose tissue, and acts as a major regulator of the hepatic acute-phase protein response and activation of CRP gene expression [20]. Mendham et al. [11] reported reductions in FM (2.9\%) and \% BF (3.7\%) alongside contemporaneous reductions in concentrations of IL-6 $\left(2.05 \pm 0.79\right.$ cf. $\left.1.35 \pm 0.43 \mathrm{pg} \mathrm{mL}^{-1}\right)$ and CRP $(2.90 \pm 0.59$ cf. $2.45 \pm 0.59 \mathrm{mg} \mathrm{L}^{-1}$ ) after 8 weeks of modified team sport activity. Similarly, Donges et al. [21] reported a reduction in $\%$ BF after 12 weeks of aerobic- and resistance-based training, which was accompanied by reductions in IL-6 concentration. In contrast, Mendham et al. [1] observed no change in IL-6 or CRP concentrations after 12 weeks of modified team sport (rugby) activity within an Indigenous Australian population who demonstrated clinical risk factors for type 2 diabetes mellitus. As such, further research is required to understand the effects of modified team sports on inflammatory status.

Much of the research to date has focused on sedentary and/or diseased populations, where the introduction of PA is likely to have a positive outcome on measures of health. However, with a proportion $(\sim 35 \%)$ of the general population in Europe not sufficiently active to meet current recommendations (150 min of moderate activity per week) [22], it is unknown if the addition of modified team sport to other forms of PA provides any additional benefit. To date, only one study has explored the effects of modified team sport using a habitually active population although the participants presented with symptoms of hypertension [23]. Additionally, much of the literature has focused on modified team sports utilising soccer that required the participant to be active for the full session. Sports such as touch rugby that allow unlimited and self-initiated interchanges might be perceived more favourably by participants enabling them to rest between bouts of activity. It was noted by Parfitt et al. [24] that allowing participant to regulate their intensity rather than be prescribed resulted in positive affective response to exercise, which likely improves the chance of continued participation [25]. Whilst the intensity cannot be fully controlled during touch rugby, the unlimited and self-initiated interchanges might reduce the overall perceived exertion. Finally, many of the reported interventions include two or more sessions per week over 12 weeks or more, which is subsequently reduced (1.3 cf. 2.4 session per week) over a prolonged period [15]. Despite this reduction in training load, body composition, cardiovascular function and some biochemical measures remained improved compared to baseline at 64 weeks. To date, only one study has reported that playing modified team sport (touch rugby) once per week over a 12-week period was beneficial for promoting health [26]. Whilst once per week is more likely to be adhered to compared to 2-3 sessions per week, further research is required to determine if once per week over a short intervention period provides any benefit when combined with habitual activity.

Accordingly, the purpose of this study was (1) to assess the effectiveness of touch rugby and interval running for promoting positive changes in blood pressure, RHR, body composition and pro-inflammatory cytokines and (2) to determine if these modes of exercise performed once per week over a 4-week period were sufficient to induce a positive change in health markers in already active participants.

\section{Methods}

\section{Participants}

With institutional ethics approval and informed consent, 16 recreationally active men (mean \pm SD: age $26.4 \pm 6.4$ years, stature $178.7 \pm 7.0 \mathrm{~cm}$ ) volunteered to participate. At the time of the study (June/August), all participants were residing in the North West of England and, in the preceding 6 months, reported via a PA questionnaire that they were completing 2-4 sessions of activity per week lasting between 30 and 60 min with the maximal combined PA of $3 \times 45 \mathrm{~min}$. Activities varied between participants, but typically included resistance training, cycling, running, circuit training and martial arts. All participants stated they were non-smokers, taking no medication and were free of any injuries or preexisting cardiovascular, inflammatory or metabolic disorders. An a priori power calculation was performed (G*Power 3.1) based on the work of Reddy et al. [27] with power at 0.80 and alpha at 0.05 . Using the results for SBP as the dependent variable, the partial eta squared, determined from the $F$ ratio and sample size was 0.43 , resulting in a required 
sample of eight participants per group and is in agreement with the previous research [28].

\section{Research design}

Participants were matched for age and physical activity (over last 6 months) and non-randomly assigned to a touch rugby $(n=8)$ or self-paced interval running $(n=8)$ group. All participants in the touch rugby group were recruited through the Play Touch Rugby League programme by the organisers and had prior experience (1-5 years) of the sport, whilst the running group was recruited via quota sampling (based on aforementioned criteria) from the general population. Both groups completed a 4-week intervention with anthropometric, physiological and biochemical measures taken before and after the intervention period. The internal, external and perceptual loads were recorded for all exercise sessions. Participants were asked to maintain their normal physical activity levels and dietary intake which was verbally confirmed each week. Participants were required to have completed no physical activity $48 \mathrm{~h}$ before, consumed no alcohol $24 \mathrm{~h}$ before and no caffeine in the $12 \mathrm{~h}$ before the pre- and postintervention assessments.

\section{Habitual physical activity}

Participant's physical activity frequency, duration, perceived intensity and type of activity were recorded using a questionnaire, with frequency determined as the absolute number of sessions, duration to the nearest quarter of an hour and perceived intensity using the following descriptors and examples: light (e.g. walking slowly or light stretching), moderate (e.g. walking briskly or swimming with moderate effort) and high (e.g. heavy resistance work).

\section{Experimental trials}

The touch rugby intervention consisted of a single 45-min match performed once a week for the 4-week period. The game consisted of six-a-side, non-contact rugby on a natural grass (width $40 \mathrm{~m}$; length $60 \mathrm{~m}$ ) pitch and adopted an unlimited interchange rule [29] with the game being played across $2 \times 20$-min halves interspersed with a 5 min rest period. All touch rugby sessions were performed on the same day of the week at the same time (19:00). Touch rugby was played with standard touch rules whereby each team had six 'plays' whilst in possession of the ball where each 'play' was concluded upon being 'touched' by an opponent. After a successful touch, the attacking team completed a 'play the ball' which involved rolling the ball backwards before a teammate retrieved the ball and passed backwards to an 'on side' player. During the 'play the ball', the defending team had to retreat $5 \mathrm{~m}$ before advancing to make the next touch. At the end of six unsuccessful touches or if a try was scored, the ball was turned over to the other team.

The running intervention was performed once per week and completed individually with the participant running around the perimeter of a $91 \times 120 \mathrm{~m}$ natural grass pitch for $2 \times 20$-min periods with 5 min rest in between. Participants were instructed to regulate and self-adjust their speed to cover the greatest distance possible whilst ensuring they continued to run for the full duration. All participants were not aware of the time that had elapsed during each session, nor was information on the internal or external demands disclosed until after the intervention period. Participants in the running group were free to choose an appropriate day and time in week 1 which was kept the same throughout the intervention period.

\section{Physical measurements}

\section{Anthropometry and body composition}

Stature was measured to the nearest millimetre $(\mathrm{mm})$ using a portable stadiometer (SECA, Leicester Height Measure, Hamburg, UK) and body mass measured to the nearest $0.1 \mathrm{~kg}$ using a calibrated electronic scale (SECA 813, SECA, Hamburg Germany). Bioelectrical impedance was measured directly using a tetra-polar device (Bodystat, 1500, Bodystat, Douglas, Isle of Man) and used to predict \%BF, FM and fat-free mass (FFM). Participants were instructed to attend euhydrated, which was confirmed by the participants on arrival, and rested in a supine position for $10 \mathrm{~min}$ before two injector electrodes and two detector electrodes were placed on the right hand and foot. This method is deemed to be reliable for measuring FFM $(r=0.998$, mean bias $=0.0 \mathrm{~kg}$, 95\% limits of agreement $(\mathrm{LoA})=-1.0$ to $1.0 \mathrm{~kg})$ [30] and percentage body fat $(r=0.876$, mean bias $=1.41 \%, 95 \%$ $\operatorname{LoA}=8.34 \%)[31]$.

\section{Blood pressure and resting heart rate}

After 10-min rest in a seated position, SBP and DBP were measured manually using an aneroid sphygmomanometer (WelchAllyn, Durashock Handheld Aneroid, Cachan, France) and stethoscope (Littmann, Select, 3 M Health Care, Neuss, Germany) to the nearest $\mathrm{mmHg}$. Simultaneously, RHR was measured using a heart rate monitor (Polar Electro, FS1, Polar Electro, Oy Finland), with the lowest value obtained during a 1-min period used for analysis [32].

\section{Blood sampling}

After 20-min rest in a seated position, a $10 \mathrm{~mL}$ sample was obtained from the median cubital vein and placed into vacutainers $(\mathrm{BD})$ containing di-potassium ethylene diamine 
tetra-aceticacid. Once separated from whole blood, plasma was analysed in duplicate to determine concentrations of circulating CRP and serum IL-6 using an enzyme-linked immunosorbent assay (ELISA; Quantikine High Sensitivity, R\&D Systems, Minneapolis, USA). The optical density for CRP and IL-6 was measured using a microplate reader (Biochrom EZ Read 400, Biochrom, Cambridge, UK) at wave lengths of 570 and $450 \mathrm{~nm}$, respectively. CRP and IL-6 were measured with an inter- and intra-coefficient of variation of between 3.8 to $7.0 \%$ and 1.6 to $3.4 \%$, respectively.

\section{Internal, external and perceptual responses}

Fifteen minutes before each session a $10 \mathrm{~Hz}$ microtechnology device fitted with a $100 \mathrm{~Hz}$ tri-axial accelerometer, gyroscope and magnetometer (Catapult, OptimEye S5, Catapult Innovations, Scoresby, Australia) was activated and positioned in a custom-made harness positioned between the scapulae. The mean number of satellites and HDOP was $15.2 \pm 3.8$ and $0.7 \pm 0.1$ for all sessions, respectively. Participants wore the same unit for all sessions. Data were recorded and analysed (Catapult Sprint version 5.1.4) for total, low- $\left(<9.0 \mathrm{~km} \mathrm{~h}^{-1}\right)$, moderate- $\left(9.1-13.0 \mathrm{~km} \mathrm{~h}^{-1}\right)$ and high-intensity distance as previously used with a similar population [33]. Mean velocity was determined for the full duration, and peak velocity was defined as the highest speed recorded during the session. Time spent above 20 weeks kg ${ }^{-1}$, PlayerLoad ${ }^{\mathrm{TM}}$ and distance covered at pre-set acceleration thresholds were measured. Mean $\left(\mathrm{HR}_{\text {mean }}\right)$ and peak $\left(\mathrm{HR}_{\text {peak }}\right)$ heart rate were also recorded using a heart rate monitor (Polar Electro, Finland, Oy) and recorded on the microtechnology device.

Immediately after the session, participants completed the Subjective Exercise Experience Scale, which was used to assess the participants' sense of positive well-being, psychological distress and fatigue [34]. In addition, participants individually provided a rating of perceived exertion using Borg's CR-10 scale [35] 10 min after each session which was multiplied by exercise duration to provide a global measure of training load [36].

\section{Statistical analysis}

Data are presented as mean and standard deviation. All dependent variables were assessed for normal distribution using the Shapiro-Wilk test. Differences in baseline values between groups for anthropometric, body composition, physiological and biochemical markers of health were investigated using an independent sample $t$ test. Whilst baseline values for each measure were not statistically different, to control the mean between-group difference at baseline, a one-factor analysis of covariance (ANCOVA) was used with the pre-to-post change as the dependent variable, intervention (i.e. touch rugby or running) as an independent variable and baseline values as a covariate. Cohens effect size was calculated from the partial eta squared result. Within-group, pre-to-post changes were assessed using a paired sample $t$ test. Independent sample $t$ tests were used to compare the internal and external demands between interventions. Perceptual measure and previous physical activity were assessed using a Mann Whitney $U$ test due to the level of measurement and non-normal distribution. In all cases, alpha was set at $P<0.05$. Furthermore, to provide an interpretation of the magnitude of change, effect sizes accompanied all inferential statistics and were calculated as the difference between trials divided by the pooled SD and the following were applied: 0.0-0.2, trivial; 0.2-0.6, small; $0.6-1.2$, moderate $; 1.2-2.0$, large $;>2.0$, very large [37]. All inferential statistics were performed using IBM SPSS (Version 26) for Macintosh (SPSS, Armonk, NY, USA).

\section{Results}

Differences in the combined frequency and duration in the preceding 6 months were not different between the touch rugby $\left(133 \pm 14 \mathrm{~min} \mathrm{week}^{-1}\right)$ and running $\left(133 \pm 21 \mathrm{~min}\right.$ week $\left.^{-1}\right)$ groups $(Z=-0.462, P=0.644)$. In all instances, participants perceived their intensity to be light-to-moderate. The average combined frequency and duration (touch rugby, $130 \pm 11 \mathrm{~min}^{\mathrm{week}}{ }^{-1}$; running, $130 \pm 24$ min week $^{-1}$ ) during the intervention period (excluding the intervention) was not different between groups $(Z=-0.427, P=0.669)$, nor was it different from that reported during the preceding 6-month period (touch rugby, $Z=-0.552, P=0.581$; running, $Z=-0.557$, $P=0.577)$.

There was no statistical difference in baseline values between the touch rugby and running group, though small mean differences were evident. The pre- and post-intervention change in body mass was not different between groups $(F=0.711, P=0.414)$ nor was there any withingroup change (touch rugby, $t=-0.694, P=0.510$; running, $t=0.467, P=0.655)$. Impedance indicated a between-group difference $(F=6.228, P=0.027)$, with a change observed for the touch rugby group $(t=4.806, P=0.002)$ but not the running group $(t=0.817, P=0.441)$. Between-group analysis revealed differences in FM $(F=9.981, P=0.008)$ and $\% \mathrm{BF}(F=9.936, P=0.008)$ with greater reductions in the touch rugby group (FM, $t=4.708, P=0.002 ; \% \mathrm{BF}, t=5.091$, $P=0.001$ ) compared to the running group (FM, $t=0.917$, $P=0.390 ; \% \mathrm{BF}, t=0.230, P=0.824)$. The change in FFM was different between groups $(F=14.673, P=0.002)$ and within-group analysis revealed significant increases after the 
touch rugby $(t=3.778, P=0.007)$ intervention but not in running $(t=1.295, P=0.236)$.

No between-group difference was observed for changes in RHR $(F=0.165, P=0.692)$ or DBP $(\mathrm{F}=2.791, P=0.119)$, but a statistical difference was evident for SBP $(F=6.748$, $P=0.022)$. The within-group change for SBP was similar for the touch rugby $(t=4.439, P=0.003)$ and running $(t=0.049, P=0.049)$ groups (Table 1$)$. There was no between-group difference in the change in CRP concentration $(F=0.530, P=0.480)$, though a within-group difference was observed for the running group $(t=3.607, P=0.009$; $\mathrm{ES}=-0.61 \pm 0.84)$ but not touch rugby group $(t=1.642$, $P=0.145 ; \mathrm{ES}=-0.33 \pm 0.83$ ) (Fig. 1). No between-group difference in the change of IL-6 was observed $(F=2.854$, $P=0.115)$, though a within-group change was observed in the touch rugby $(t=4.640, P=0.002 ; \mathrm{ES}=-1.32 \pm 0.91)$ and running group $(t=2.379, P=0.049 ; \mathrm{ES}=-0.75 \pm 0.85)$ (Fig. 1).

Between-group differences in measures of external, internal and perceptual training load as well as positive wellbeing, psychological distress and feeling of fatigue are presented in Table 2.

\section{Discussion}

This study investigated the effectiveness of a short intervention consisting of touch rugby or self-paced interval running for improving markers of health in an active group of young men. The main finding was that 4 weeks of touch rugby and interval running, in addition to their habitual activity, resulted in a marked reduction in SBP, whilst the touch intervention appeared more effective for reducing $\mathrm{FM}$ and $\% \mathrm{BF}$ as well as increasing FFM. Markers of low-grade systemic inflammation were, on average, reduced over the intervention period, with no between-group difference observed. The external and internal demands differed between interventions, with touch rugby eliciting greater high-intensity running, peak velocity, time above 20 weeks $\mathrm{kg}^{-1}$, accelerated running and feeling of positive well-being compared to self-paced interval running. In contrast, the self-paced running group covered greater total- low-intensity and moderate-intensity running and demonstrated higher internal and perceptual loads.

Both interventions appeared effective at reducing FM after only 4 weeks (touch, $-2.8 \mathrm{~kg}$; running, $-0.4 \mathrm{~kg}$ ). This finding reaffirms similar reductions after 12 weeks of modified team sport (soccer) $(-2.7 \mathrm{~kg})$ and steady-state running $(-1.8 \mathrm{~kg})$ [15] and 8 weeks of modified team sport (touch rugby) $(-0.7 \mathrm{~kg})$ and cycling $(-0.8 \mathrm{~kg})$ [2]. Our results suggest that touch rugby was more effective for reducing FM and \% BF compared to running when controlling for baseline differences, which is likely explained by the different

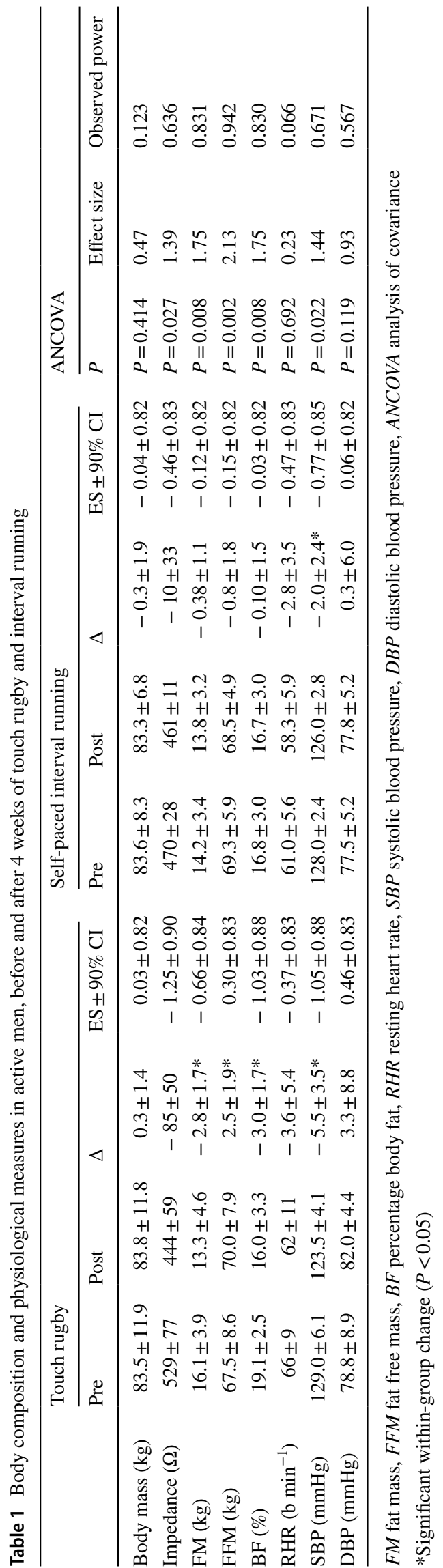


Fig. 1 Fasting blood chemistry of inflammatory cytokines, interleukin-6 (top panel) and C-reactive protein (bottom panel) before and after 4 weeks of touch rugby and self-paced interval running. ${ }^{*}$ Within-group change $(P<0.05)$
Table 2 External, internal and perceptual responses during the touch rugby and running
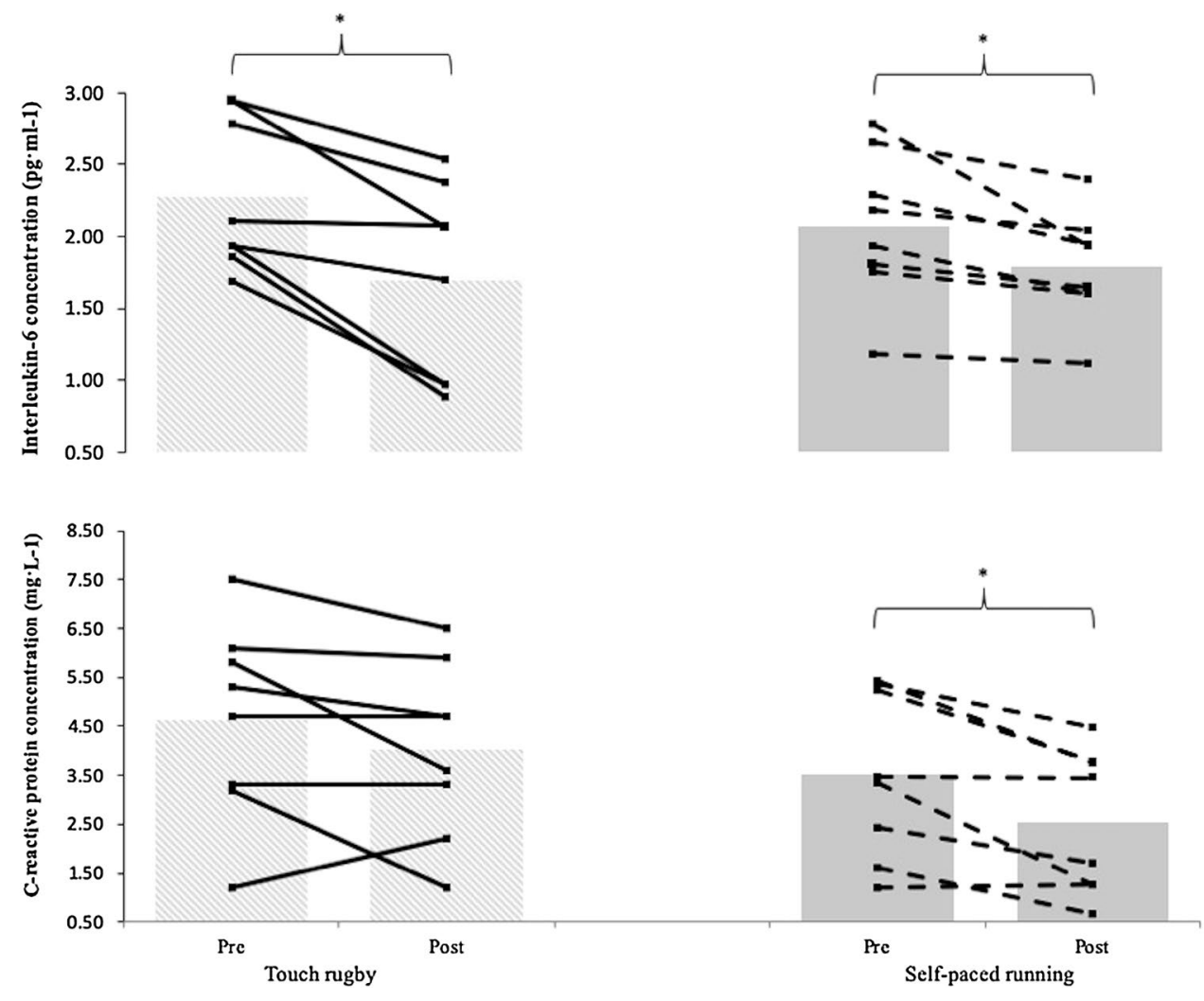

\begin{tabular}{|c|c|c|c|}
\hline Variable & Touch rugby & $\begin{array}{l}\text { Self-paced interval } \\
\text { running }\end{array}$ & $\begin{array}{l}\text { Effect } \\
\text { size } \pm 90 \% \text { CI }\end{array}$ \\
\hline \multicolumn{4}{|l|}{ External load } \\
\hline Distance $\left(\mathrm{m} \mathrm{min}^{-1}\right)$ & $70.8 \pm 13.5$ & $141.4 \pm 19.8 *$ & $-4.16 \pm 0.73$ \\
\hline Low intensity distance $\left(\mathrm{m} \mathrm{min}^{-1}\right)$ & $39.9 \pm 9.1$ & $65.6 \pm 33.9^{*}$ & $-1.04 \pm 0.44$ \\
\hline Moderate intensity distance $\left(\mathrm{m} \mathrm{min}^{-1}\right)$ & $16.4 \pm 4.6$ & $71.7 \pm 41.5^{*}$ & $-1.87 \pm 0.49$ \\
\hline High intensity distance $\left(\mathrm{m} \mathrm{min}^{-1}\right)$ & $9.4 \pm 2.7 *$ & $2.3 \pm 4.6$ & $1.88 \pm 0.49$ \\
\hline Mean velocity $\left(\mathrm{km} \mathrm{h}^{-1}\right)$ & $4.20 \pm 0.8$ & $8.48 \pm 1.2^{*}$ & $-4.20 \pm 0.74$ \\
\hline Peak velocity $\left(\mathrm{km} \mathrm{h}^{-1}\right)$ & $25.1 \pm 3.8^{*}$ & $13.8 \pm 1.9$ & $3.76 \pm 0.68$ \\
\hline Time above 20 weeks kg ${ }^{-1}$ (s) & $103 \pm 23^{*}$ & $89 \pm 13$ & $-0.57 \pm 0.34$ \\
\hline Acceleration: $0-2 \mathrm{~m} \mathrm{~s}^{-1}\left(\mathrm{~m} \mathrm{~min}^{-1}\right)$ & $39.5 \pm 8.3$ & $85.9 \pm 12.5^{*}$ & $-4.32 \pm 0.76$ \\
\hline Acceleration: $2-3 \mathrm{~m} \mathrm{~s}^{-1}\left(\mathrm{~m} \mathrm{~min}^{-1}\right)$ & $1.4 \pm 0.4^{*}$ & $0.1 \pm 0.1$ & $4.40 \pm 0.76$ \\
\hline Acceleration: $3-4 \mathrm{~m} \mathrm{~s}^{-1}\left(\mathrm{~m} \mathrm{~min}^{-1}\right)$ & $0.6 \pm 0.2 *$ & $0.0 \pm 0.0$ & $4.06 \pm 0.72$ \\
\hline Acceleration: $4-20 \mathrm{~m} \mathrm{~s}^{-1}\left(\mathrm{~m} \mathrm{~min}^{-1}\right)$ & $0.5 \pm 0.1 *$ & $0.0 \pm 0.0$ & $6.17 \pm 0.99$ \\
\hline Player load (AU) & $304.0 \pm 62.2$ & $817.3 \pm 176.4^{*}$ & $4.67 \pm 0.72$ \\
\hline \multicolumn{4}{|l|}{ Internal load } \\
\hline Mean heart rate $\left(\% \mathrm{HR}_{\text {peak }}\right)$ & $71.8 \pm 9.0$ & $80.6 \pm 6.5^{*}$ & $-1.12 \pm 0.44$ \\
\hline Peak heart rate $\left(\% \mathrm{HR}_{\text {peak }}\right)$ & $93.0 \pm 8.9$ & $95.3 \pm 4.1$ & $-0.33 \pm 0.41$ \\
\hline \multicolumn{4}{|l|}{ Perceptual load } \\
\hline NsRPE $\times$ time $(A U)$ & $166.3 \pm 77.9$ & $239.1 \pm 81.2^{*}$ & $-0.91 \pm 0.43$ \\
\hline Positive well-being (AU) & $22.0 \pm 4.2$ & $20.4 \pm 4.4$ & $0.37 \pm 0.41$ \\
\hline Psychological distress (AU) & $6.5 \pm 3.6$ & $7.1 \pm 3.5$ & $-0.17 \pm 0.41$ \\
\hline Fatigue (AU) & $11.3 \pm 4.8$ & $13.6 \pm 5.2$ & $-0.46 \pm 0.42$ \\
\hline
\end{tabular}

$\% H R_{\text {peak }}$ percentage of peak heart rate, $s R P E$ session rating of perceived exertion, $A U$ arbitrary units

*Significant within-group change $(P<0.05)$ 
external loads imposed by the respective interventions. For example, the touch group covered more high-intensity running, time above 20 weeks kg${ }^{-1}$ and distance at the higher acceleration thresholds when compared to the running group and may have resulted in a greater energy expenditure [38]. This notwithstanding, both groups appeared to induce positive changes in FM and \%BF, suggesting that one 45-min high-intensity activity in addition to their habitual activity was beneficial for improving body composition.

In contrast to the running group, an increase in FFM was observed for the touch rugby group, supporting the findings of Mendham et al. [11] who reported a $1.1 \mathrm{~kg}$ increase in FFM after 8 weeks of touch rugby in sedentary middleaged men. Whilst the increase observed after touch rugby was of greater magnitude than that reported by Mendham et al. [11], this findings might be due to the activity levels of the participants both before and during the intervention period as well as differences in methods. Mendham et al. [11] used dual-energy X-ray absorptiometry (DEXA), which is regarded as an accurate, non-invasive technique for assessing body composition [39]. However, due to the cost and expertise required with DEXA, this study used bioelectrical impedance, which provides a doubly indirect assessment. Notwithstanding these differences, our results support the notion that the movement demands associated with modified team sports are important for eliciting positive changes in estimates of FFM [2, 10, 11, 17]. The running group experienced no meaningful change in FFM, which confirms similar observations by Krustrup et al. [15] after 12 weeks of running. These results suggest that greater time above 20 weeks kg${ }^{-1}$ and number of accelerations and decelerations, which are indicative of high mechanical loading, appears important for promoting FFM [10].

The reduction in SBP after 4 weeks of touch rugby and running ( -5.5 and $-2.0 \mathrm{mmHg}$, respectively) is of sufficient magnitude to be clinically meaningful [40] and concurs with similar values reported after 12 and 24 weeks of modified team sport (soccer) in untrained [15] and diabetic men [13], respectively. Controlling for baseline difference, it appeared the touch intervention was more effective for lowering SBP while no between-group difference was apparent for DBP. Resting heart rate was lower after both the touch rugby $(-4$ beats $\min ^{-1}$ ) and running $\left(-3\right.$ beats $\min ^{-1}$ ) interventions and was similar in magnitude to that reported previously in sedentary and untrained adults $\left(\sim 3-6\right.$ beats $\left.\min ^{-1}\right)[15$, 26]. While it is important to note that the change between groups was not different, the within-group change revealed a small effect size for both groups and might be indicative of a reduction in sympathetic outflow, vasoconstrictor state of the peripheral vasculature and vascular remodelling $[10,15$, 41]. Whilst this supports previous research, it is important to acknowledge that the change observed was within the reported day-to-day variability (3-4 beats $\mathrm{min}^{-1}$ ) of RHR
[42] and that further research is required to confirm these findings after a short-term intervention.

Previous research has reported reductions in IL-6 and CRP amongst other pro- and anti-inflammatory cytokines after a period of modified team sport activity $[1,21]$, agreeing with these findings after four weeks of touch rugby and self-paced interval running. Both interventions demonstrated a reduction in IL-6 after 4 weeks of training whereas CRP was highly variable with a within-group change observed only after the running intervention. Mendham et al. [11] observed a reduction in IL- 6 and CRP after 8 weeks of touch rugby in sedentary middle-aged men, which was accompanied by a concomitant reduction in FM and \%BF. Furthermore, Mendham et al. [1] observed a reduction in CRP after 12 weeks of multi-sport activity despite lack of change in IL-6 over the same period. It is, however, important to note that the participants used in the latter study were clinically obese and presented clinical risk factors for diabetes. Our results support the notion that modified team sports might be effective for reducing IL-6, though it is possible that 4 weeks was not sufficient for some individuals and that a longer intervention period is required to detect changes in CRP that exceed the day-to-day variability (coefficient of variation $3.8-7.0 \%)$.

Touch rugby elicited a lower rating of perceived exertion compared to the running group, which might be important when concerning exercise adherence [43]. Though not statistically different, our results for perceived well-being, fatigue and psychological distress support those of Mendham et al. [44] who reported participation in touch rugby was perceived to be less challenging $(6.6 \pm 2.0 \mathrm{cf} .7 .4 \pm 1.8 \mathrm{AU})$ and more 'fun' ( $6.6 \pm 0.5$ cf. $5.2 \pm 1.3 \mathrm{AU})$ when compared to cycle ergometry. These findings are important when considering modified team sports as a long-term health promotion activity. For example, sports such as touch rugby, which allows multiple interchanges, are likely to result in a reduction in the perceived exertion and greater positive-affective responses to exercise, thus strengthening the intentions for continued participation [25].

Despite our results showing that the addition of one touch rugby or self-paced running session per week can improve the health of active men, this study is not without its limitations. First, it is important to note that the sample size included was based on a single dependent variable and that the results for others might be underpowered and therefore, caution should be taken when interpreting those with a low observed power. Second, a control group was not included within the study design and therefore it is unknown if either intervention was beneficial compared to habitual activity alone. Further, the participants were not randomly allocated to a training group, which has important implication due to the risk of selection bias and more specifically, inclusive bias with reference to the PTRL group. As such, whether 
these findings can be extrapolated to other groups or a wider population remains unknown. Whilst the lack of randomisation is problematic, we did match the groups, and the statistical approach used would account for any initial mean baseline differences between groups. Finally, our analysis was limited to two key markers of inflammation and as such, future research might wish to investigate additional markers of chronic low-grade systemic inflammation such as TNF- $\alpha$ and IL-18.

\section{Conclusion}

Our results reaffirm that participation in a modified team sport and self-paced running is beneficial for promoting measures of health when combined with their habitual activity. The external demands associated with the touch rugby intervention indicated that greater vigorous activity and distance accelerating at higher thresholds was performed which might be important and responsible for the greater changes in SBP and body composition when compared to self-paced running. Further, as touch rugby allows self-selected and unlimited interchanges, it might serve to promote sustained participation due to the lower rating of perceived exertion and fatigue as well as greater positive well-being compared to self-paced interval running. Overall, the results of this study demonstrate that one additional session per week of touch rugby or interval running was sufficient in promoting a number of health measures in young men who were active but not meeting current physical activity guidelines.

\section{Compliance with ethical standards}

Conflict of interest The authors declare that they have no competing interests.

Ethical approval This research was approved by the Faculty of Life Sciences Ethics Committee at the University of Chester (Ref No. 1010/15/ $\mathrm{ND} / \mathrm{SES}$ ) and conformed to the principles of outlined in the Declaration of Helsinki.

Informed consent Written consent was obtained from all participants.

Open Access This article is licensed under a Creative Commons Attribution 4.0 International License, which permits use, sharing, adaptation, distribution and reproduction in any medium or format, as long as you give appropriate credit to the original author(s) and the source, provide a link to the Creative Commons licence, and indicate if changes were made. The images or other third party material in this article are included in the article's Creative Commons licence, unless indicated otherwise in a credit line to the material. If material is not included in the article's Creative Commons licence and your intended use is not permitted by statutory regulation or exceeds the permitted use, you will need to obtain permission directly from the copyright holder. To view a copy of this licence, visit http://creativecommons.org/licenses/by/4.0/.

\section{References}

1. Mendham AE, Duffield R, Marino F, Coutts AJ (2014) A 12 week sport-based exercise programme for inactive Indigenous Australian men improved clinical risk factors associated with type 2 diabetes mellitus. J Sci Med Sport 18(4):438-443

2. Mendham AE, Duffield R, Coutts AJ, Marino F, Boyko A, Bishop D (2015) Rugby-specific small-sided games training is an effective alternative to stationary cycling at reducing clinical risk factors associated with the development of type 2 diabetes: a randomized, controlled trial. PLoS ONE 10(6):e0127548. https://doi. org/10.1371/journal.pone.0127548

3. Downward P, Rasciute S (2015) Exploring the covariates of sport participation for health: an analysis of males and females in England. J Sports Sci 33(1):67-76

4. Connolly LJ, Bailey SJ, Krustrup P, Fulford J, Smietanka C, Jones AM (2017) Effects of self-paced interval and continuous training on health markers in women. Eur J Appl Physiol 177(11):2281-2293

5. Weston M, Taylor KL, Batterham AM, Hopkins WG (2014) Effects of low-volume high-intensity interval training (HIT) on fitness in adults: a meta-analysis of controlled and non-controlled trials. Sports Med 44(7):1005-1017

6. Patterson S, Pattison J, Legg H, Gibson AM, Brown N (2017) The impact of badminton on health markers in untrained females. J Sports Sci 35(11):1098-1106

7. Krustrup P, Bangsbo J (2015) Recreational football is effective in the treatment of non-communicable disease. Br J Sports Med 49(22):1426-1427

8. Schmidt JF, Hansen PR, Andersen TR, Andersen LJ, Hornstrup $\mathrm{T}$ et al (2014) Cardiovascular adaptations to 4 and 12 months of football or strength training in 65- to 75-year old untrained men. Scand J Med Sci Sports 24:86-97

9. Randers MB, Petersen J, Andersen LJ, Krustrup BR, Hornstrup $T$ et al (2012) Short-term street soccer improves fitness and cardiovascular health status of homeless men. Eur J Appl Physiol 112(6):2097-2106

10. Krustrup P, Christensen JF, Randers MB, Pedersen H, Sundstrup $E$ et al (2010) Muscle adaptation and performance enhancement of soccer training for untrained men. Eur J Appl Physiol 108(6):1247-1258

11. Mendham AE, Duffield R, Marino F, Coutts AJ (2014) Smallsided games training reduced CRP, IL-6 and leptin in sedentary, middle-aged men. Eur J Appl Physiol 114(11):2289-2297

12. Andersen TR, Schmidt JF, Thomassen M, Hornstrup T, Frandsen U et al (2014) A preliminary study: effects of football training on glucose control, body composition, and performance in men with type 2 diabetes. Scand J Med Sci Sports 24(Suppl 1):43-56

13. Uth J, Hornstrup T, Chestensen JF, Christensen KB, Jorgensen NR et al (2016) Efficacy of recreational football on bone health, body composition, and physical functioning in men with prostate cancer undergoing androgen deprivation therapy: a 32-week follow-up of the FC prostate randomised controlled trial. Osteo Int 27(4):1507-1518

14. Nielsen G, Wikman JM, Jensen CJ, Schmidt JF, Gilemann L, Andersen TR (2014) Health promotion: the impact of beliefs of health benefits, social relations and enjoyment on exercise continuation. Scan J Med Sci Sports 24(1):66-75

15. Krustrup P, Nielsen JJ, Krustrup BR, Christensen JF, Pedersen H et al (2009) Recreational soccer is an effective health-promoting activity for untrained men. Br J Sports Med 43(11):825-831

16. Mohr M, Lindenskov A, Holm PM, Nielsen HP, Mortensen J et al (2014) Football training improves cardiovascular health profile in sedentary, premenopausal hypertensive women. Scand J Med Sci Sports 24(1):36-42 
17. Randers MB, Nielsen JJ, Krustrup BR, Sundstrup S, Jakobsen MD et al (2010) Positive performance and health effects of a football training program over 12 weeks can be maintained over a 1-year period with reduced training frequency. Scand J Med Sci Sports 20(Suppl 1):80-89

18. Wärnberg J, Cunningham K, Romeo J, Marcos A (2010) Physical activity, exercise and low-grade systemic inflammation. Proc Nutr Soc 69:400-406

19. You T, Arsenis NC, Disanzo BL, Lamonte MJ (2013) Effects of exercise training on chronic inflammation in obesity: current evidence and potential mechanisms. Sports Med 4(4):243-256

20. Memoli B, Procino A, Calabrò P, Esposito P, Grandaliano $G$ et al (2007) Inflammation may modulate Il-6 and C-reactive protein gene expression in the adipose tissues: the role of IL-6 cell membrane receptor. Am J Physiol Endocriol Metab 293(4):E1030-E1035

21. Donges CE, Duffield R, Guelfi KJ, Smith GC, Adams DR, Edge JA (2013) Comparative effects of single-mode vs. duration-matches concurrent exercise training on body composition, low-grade inflammation, and glucose regulation in sedentary, overweight, middle-aged men. Appl Physiol Nutr Metab 38(7):779-788

22. Hallal PC, Andrsen LB, Bull FC, Guthold R, Haskell W et al (2012) Global physical activity levels: surveillance progress, pitfalls, and prospects. Lancet 380(9838):21-27

23. Knoepfli-Lenzin C, Sennhauser C, Toigo M, Boutellier U, Bangsbo J et al (2010) Effects of a 12 week intervention period with football and running for habitually active men with mild hypertension. Scand J Med Sci Sports 20(Suppl 1):72-79

24. Parfitt G, Rose EA, Burgess WM (2006) The psychological and physiological response of sedentary individuals to prescribed and preferred intensity exercise. Br J Health Psych 11:39-53

25. Kwan BM, Bryan AD (2010) Affective responses to exercise as a component of exercise motivation: attitudes, norms, selfefficacy, and temporal stability of intentions. Psych Sport Exerc 11(7):71-79

26. Filliau C, Younes M, Blanchard AL, Piscione J, Van de Louw A et al (2015) Effects of "touch rugby" training on the cardiovascular autonomic control in sedentary subjects. Int J Sports Med 36(7):567-572

27. Reddy P, Dias I, Holland C, Campbell N, Nagar I et al (2017) Walking football as sustainable exercise for older adults - a pilot investigation. Eur J Sport Sci 17(5):638-645

28. Seabra A, Serra H, Seabra A, Brito J, Krustrup P et al (2016) Effect of a 6-month football intervention program on bone mass and physical fitness in overweight children. Spine Res. https://doi. org/10.21767/2471-8173.100009

29. Kennett DC, Kempton T, Coutts AJ (2012) Factors affecting exercise intensity in rugby-specific small-sided games. J Strength Cond Res 26(8):2037-2042

30. Kilduff LP, Lewis S, Kingsley MIC, Owen NJ, Dietzig RE (2007) Reliability and detecting change following short-term creatine supplementation: comparison of two-component body composition methods. J Strength Cond Res 21(2):378-384
31. Batterham M, Tapsell LC, Jenkins A (2002) A comparison of bioelectrical impedance and near infra-red interactance with dual energy X-ray absorptiometry for the determination of body fat. Nutr Diet 59(2):120-126

32. Schmidt JF, Andersen TR, Horton J, Brix J, Tarnow L et al (2013) Soccer training improves cardiac function in men with type 2 diabetes. Med Sci Sports Exerc 45(12):2223-2233

33. Randers MB, Nielsen JJ, Bangsbo J, Krustrup P (2014) Physiological responses and activity profiles in recreational small-sided football: no effect of the number of players. Scand J Med Sci Sports 24(Suppl 1):130-137

34. McAuley E, Courneya KS (1994) The subjective exercise experience scale (SEES): development and preliminary validation. $\mathbf{J}$ Sport Exerc Psych 16:163-177

35. Borg G, Ljunggren G, Ceci R (1985) The increase of perceived exertion, aches and pain in the legs, heart rate and blood lactate during exercise on a bicycle ergometer. Eur J Appl Physiol Occup Physiol 54(4):343-349

36. Foster C, Florhaug JA, Franklin J, Gottschall L, Hrovatin LA et al (2001) A new approach to monitoring exercise training. J Strength Cond Res 15(1):109-115

37. Hopkins WA (2002) Scale of magnitude for effect statistics. Sportscience available at: https://www.sportsci.org/resource/stats /effectmag.html. Accessed 27 July 2019

38. Oxendale CL, Highton J, Twist C (2017) Energy expenditure, metabolic power and high speed activity during linear and multidirectional running. J Sci Med Sport 20(10):957-961

39. Branski LK, Norbury WB, Herndon DN, Chinkes DL, Coachran A et al (2010) Measurement of body composition: is there a gold standard. J Parenter Enteral Nutr 34(1):55-63

40. Pedersen BK, Saltin B (2006) Evidence for prescribing exercise as therapy in chronic disease. Scan J Med Sci Sports 16(Suppl 1):3-63

41. Pescatello LS, Franklin BA, Fagard R, Farguhar WB, Kelley GA, Ray CA (2004) American College of Sport Medicine position stand. Exercise and hypertension. Med Sci Sports Exerc 36(5):533-553

42. Achten J, Jeukendrup AE (2003) Heart rate monitoring: applications and limitations. Sports Med 33(7):517-538

43. Lovell GP, Ansari WE, Parker JK (2010) Perceived exercise benefits and barriers of non-exercising female university students in the United Kingdom. Int J Environ Res Public Health 7(3):784-798

44. Mendham AE, Coutts AJ, Duffield R (2012) The acute effects of aerobic exercise and modified rugby on inflammation and glucose homeostasis within Indigenous Australians. Eur J Appl Physiol $112: 3787-4379$

Publisher's Note Springer Nature remains neutral with regard to jurisdictional claims in published maps and institutional affiliations. 